\title{
Towards improved, cost-effective surveillance of Ixodes ricinus ticks and associated pathogens using species distribution modelling
}

\author{
Manuela Signorini, ${ }_{1}$ Anna-Sofie Stensgaard, ${ }^{2}$ Michele Drigo, ${ }_{1}^{1}$ Giulia Simonato, ${ }^{1}$ \\ Federica Marcer, ${ }^{1}$ Fabrizio Montarsi, ${ }^{3}$ Marco Martini, ${ }^{1}$ Rudi Cassini ${ }^{1}$ \\ ${ }^{1}$ Department of Animal Medicine, Production and Health, University of Padua, Legnaro (PD), Italy; \\ ${ }^{2}$ Center for Macroecology, Evolution and Climate, Natural History Museum of Denmark, \\ University of Copenhagen, Copenhagen, Denmark; ${ }^{3}$ Istituto Zooprofilattico Sperimentale delle Venezie, \\ Legnaro (PD), Italy
}

\author{
Correspondence: Rudi Cassini, Department of Animal Medicine, \\ Production and Health, University of Padua, viale dell'Università 16, \\ 35020 Legnaro (PD), Italy. \\ Tel.: +39.049.8272777. \\ E-mail: rudi.cassini@unipd.it
}

Key words: Ixodes ricinus; Italy; Species distribution models; Remote sensing; Ticks.

Acknowledgements: the authors thank Alessandra Mondin for the technical support with molecular analyses.

Contributions: MS, RC study design; MS, ASS, MD, FM, RC data collecting and analyzing; MS, ASS, RC manuscript writing; ASS, MD, GS, FM, MM manuscript reviewing and reference search.

Conflict of interest: the authors declare no potential conflict of interest.

Funding: the work was supported by a grant from the University of Padua "Integrated surveillance of vector-borne diseases using Geographic Information Systems (GIS)" - Project code CPDA083110. ASS is grateful to Knud Højgaards Foundation for supporting the Research Platform for Disease Ecology, Climate and Health and thanks the Danish National Research Foundation for its support of the Center for Macroecology, Evolution and Climate (grant no. DNRF96).

Conference presentation: part of this paper was presented at the International Congress "One World - One Health - One Vision", 2015, October 14-16, Sarajevo, Bosnia and Herzegovina, and at the 4th Italian Congress on Wildlife Eco-pathology, 2017, October 11-13, Domodossola, Italy.

Received for publication: 16 October 2018.

Revision received: 28 November 2018.

Accepted for publication: 28 November 2018.

(C) Copyright M. Signorini et al., 2019

Licensee PAGEPress, Italy

Geospatial Health 2019; 14:745

doi:10.4081/gh.2019.745

This article is distributed under the terms of the Creative Commons Attribution Noncommercial License (CC BY-NC 4.0) which permits any noncommercial use, distribution, and reproduction in any medium, provided the original author(s) and source are credited.

\begin{abstract}
Various ticks exist in the temperate hilly and pre-alpine areas of Northern Italy, where Ixodes ricinus is the more important. In this area different tick-borne pathogen monitoring projects have recently been implemented; we present here the results of a twoyear field survey of ticks and associated pathogens, conducted 2009-2010 in North-eastern Italy. The cost-effectiveness of different sampling strategies, hypothesized a posteriori based on two sub-sets of data, were compared and analysed. The same two subsets were also used to develop models of habitat suitability, using a maximum entropy algorithm based on remotely sensed data. Comparison of the two strategies (in terms of number of ticks collected, rates of pathogen detection and model accuracy) indicated that monitoring at many temporary sites was more cost-effective than monthly samplings at a few permanent sites. The two model predictions were similar and provided a greater understanding of ecological requirements of I. ricinus in the study area. Dense vegetation cover, as measured by the normalized difference vegetation index, was identified as a good predictor of tick presence, whereas high summer temperatures appeared to be a limiting factor. The study suggests that it is possible to obtain realistic results (in terms of pathogens detection and development of habitat suitability maps) with a relatively limited sampling effort and a wellplanned monitoring strategy.
\end{abstract}

\section{Introduction}

In Europe, the tick Ixodes ricinus (L.) is one of the most important vectors of viruses, bacteria and parasites, responsible for the spread of many zoonotic diseases (e.g., tick-borne encephalitis, Lyme disease or borreliosis, rickettsiosis, human babesiosis and human granulocytic anaplasmosis). In recent years a general increase in the geographical range and incidence of these zoonotic diseases has been observed in Europe (Gray et al., 2009, 2010; Medlock et al., 2013; Bergquist et al., 2018). In Italy, I. ricinus is reported throughout the peninsula, particularly in temperate hilly and pre-alpine northern areas, where some ticks and tickborne pathogens (TBPs) monitoring projects have been implemented recently (Piccolin et al., 2006; Nazzi et al., 2010; Capelli et al., 2012; Ceballos et al., 2014). 
Due to the complexity related to the emergence of vector-borne diseases, an integrated approach to surveillance is encouraged (Braks et al., 2011). A prime objective of surveillance of TBPs is to assess the panel of pathogens occurring in a given area, estimating their prevalence both in tick populations and in reservoir hosts. Secondly, information on tick distribution, density and seasonal dynamics should be acquired (Capelli et al., 2012). Ticks are strongly influenced by climatic and environmental variables, such as temperature, relative humidity, rainfall and vegetation cover (Ruiz-Fons et al., 2012; Estrada-Peña et al., 2013), something that contributes to the changing geographical patterns of the TBPs (Dantas-Torres et al., 2012).

A better understanding of the climatic and habitat characteristics that determine the patterns of tick distribution can be obtained through ecological studies and modelling, and can subsequently be used to predict their current distributions over continuous surfaces.

Species distribution models (SDMs), widely used in biodiversity research for modelling species geographic distributions based on correlations between known occurrence records and the environmental conditions at those localities (Elith and Leathwick, 2009), have also proven to be a useful tool in disease epidemiology. In fact, SDMs have been widely used in biogeographical and ecological studies of vectors and vector-borne diseases (IlloldiRangel et al., 2012; Mughini-Gras et al., 2013; Mwase et al., 2014; Signorini et al., 2014).

In the present study, using data from a 2-years field monitoring activity of ticks and tick-associated pathogens conducted in a limited area of north-eastern Italy (Drigo et al., 2011), we set out to determine the optimal approach to the surveillance of ticks and associated pathogens; we did so by: i) comparing the cost-effectiveness of different sampling strategies for detection of ticks and associated pathogens using two different sub-sets of field data; ii) developing and comparing the outputs of two species distribution models (MaxEnt) based on remotely sensed environmental variables and the two field data-subsets.

\section{Materials and Methods}

\section{Study area}

The study area comprised the Colli Euganei Regional Park $\left(45^{\circ} 13^{\prime}-45^{\circ} 24^{\prime} \mathrm{N} ; 11^{\circ} 13^{\prime}-11^{\circ} 48^{\prime} \mathrm{E}\right)$, a hilly area of volcanic origin, located in the central part of Veneto Region, North-eastern Italy (Figure 1). The Park occupies a small area of approximately $180 \mathrm{~km}^{2}$. The area has near-Mediterranean environmental and climatic characteristics and human activities in the park include agriculture, tourism and recreation. Due to these characteristics, there is a potential risk for I. ricinus presence and infections associated with this tick. The altitudinal ranges from 0 to $601 \mathrm{~m}$ above the mean sea level. The climate is characterized by mild winters (minimum $-6^{\circ} \mathrm{C}$ ) and moderately hot summers (maximum $36^{\circ} \mathrm{C}$ ). The annual mean amount of precipitation is $850 \mathrm{~mm}$ characterized by two peaks, one in spring (April) and one in autumn (between October and November) and two minima in summer (July) and winter (between January and February). On average, there are 80 days with precipitation per year.

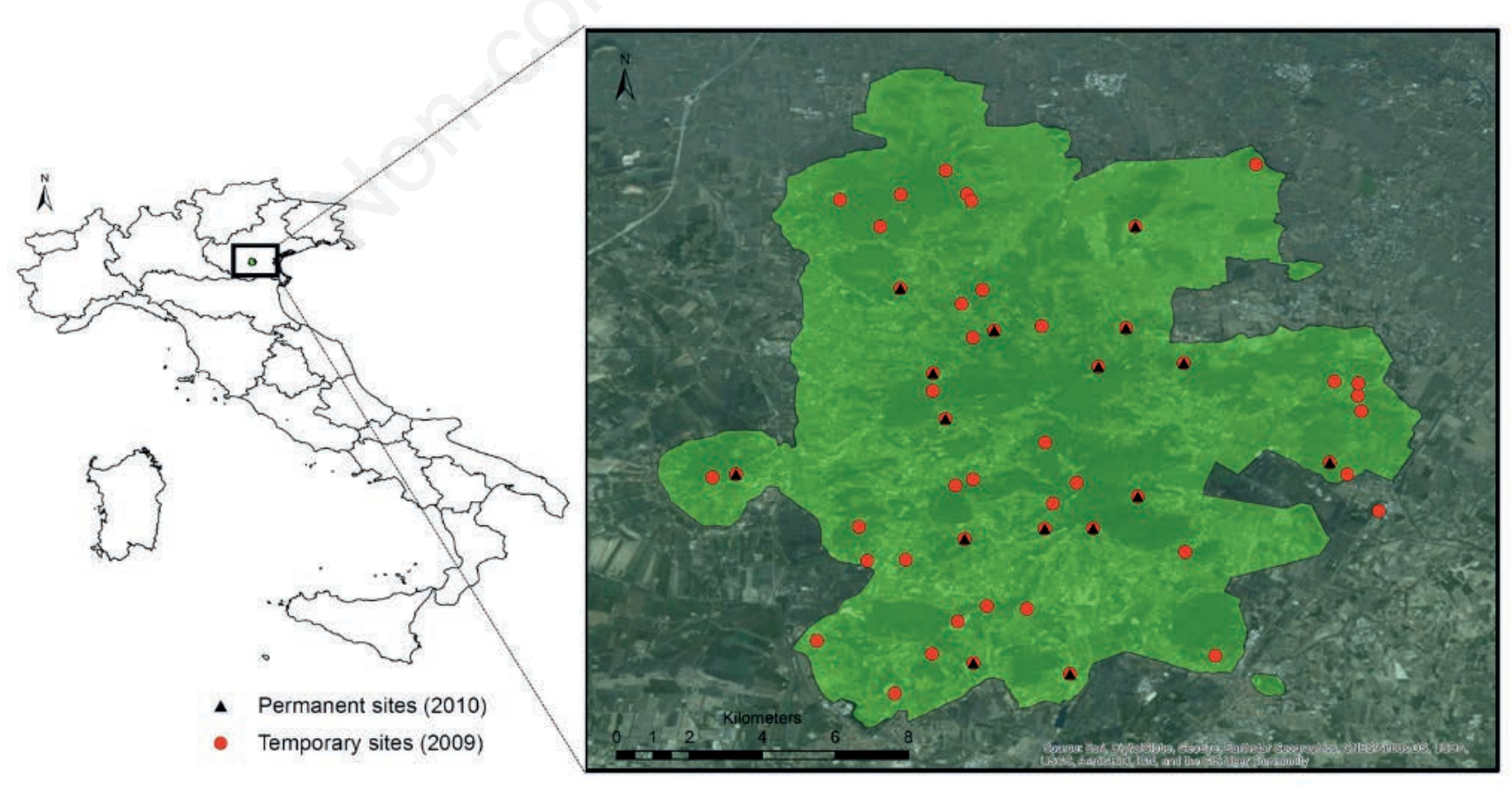

Figure 1. Study area and tick dragging sites. 
The territory spans a wide range of vegetation types (e.g., Mediterranean scrub, arid meadows, woodlands mainly consisting of chestnut, oak and Robinia) harbouring a diverse wildlife (e.g., fox, weasel, badger, small insectivorous mammals, rodents, fallow deer and wild boar) that may act as hosts and/or provide blood meals for I. ricinus ticks.

\section{Tick collection and molecular analyses}

The study is based on field data collected during the tick activity seasons in 2009 and 2010. Collections were performed by dragging a $1 \mathrm{~m}$ white flannel cloth along a transect of $100 \mathrm{~m}$ and examining it at 5-m intervals. Collected specimens were pooled together in vials keeping them alive, identified according to morphological features in the laboratory (Manilla and Iori, 1992; Cringoli et al., 2005) and then stored at $-20^{\circ} \mathrm{C}$, for further molecular detection of TBPs. Overall, 52 sites were monitored during the two years, with a total of 188 sessions of dragging (Figure 1). During the first year (2009), 52 sites were identified and sampled between April and October to assess the tick distribution in the study area: four out of the 52 sites, were sampled on a monthly basis for 7 months, whereas all other 48 sites were visited only once that year. Then, in 2010, to better examine ticks seasonality, 16 of the original 52 sites were randomly selected and monitored monthly from April to October (112 drags). Each site was geo-referenced using GPS (Juno SB Trimble, USA).

Molecular analyses were performed on single adult ticks and on pooled sampled of nymphs (1 to 10$)$ and larvae (1 to 20$)$, following the methodology described in detail in Drigo et al. (2011). Briefly, a multiplex real-time polymerase chain reaction (PCR) test was performed with the aim to detect Anaplasma phagocytophilum and Borrelia burgdorferi s.l., using primers and probes described by Courtney et al. (2004) in the Roche LightCycler. Rickettsia spp. detection was conducted with a conventional PCR targeted at gltA gene, as described by Regnery et al. (1991).

\section{Comparison of monitoring strategies}

Two different monitoring strategies were hypothesized $a$ posteriori, based on two sub-sets of data. Strategy 1 included the 16 permanent sites sampled monthly from April to October 2010 (112 dragging sessions), while Strategy 2 included only one annual sampling of the 52 sites monitored ( 52 dragging sessions) in 2009. For each strategy, the sampling effort (number of sampled sites; number of dragging) and the relative output (number of positive sites; number of ticks collected; prevalence of pathogens) were calculated and compared.

\section{Modelling tick distribution and habitat suitability}

To investigate environmental and/or climatic predictors of tick occurrence and to produce maps of tick habitat suitability, one of the most commonly used programmes for modelling species distributions from presence data only, MaxEnt, was chosen (Phillips et al., 2006). This approach is based on a machine-learning algorithm that estimates the distribution across geographic space combining a set of environmental data with presence localities and background records (pseudo absences) sampled from the overall study area (Phillips and Dudik, 2008).

Two different models were fitted, using the sub-set of occurrence data of strategies 1 (Model 1) and 2 (Model 2), to compare the impact of the different sampling strategies on the model output in terms of predicted tick distributions. We used MaxEnt software, version 3.3.3k (http://www.cs.princeton.edu/schapire/maxent/) with its default settings, but only the linear and quadratic features were employed (Phillips et al., 2004). The MaxEnt model outputs were set to logistic, which returns an estimated relative probability of species presence at a given location ranging from 0 (low probability) up to 1 (very high relative probability). We used a 10 -fold cross-validation and assessed predictive performance using the area under the receiver operating characteristic curve, to measure the ability of the model predictions to separate presence from the background (pseudo-absences). For model validation, the leaveone-out or jackknife procedure, proposed by Pearson et al. (2007), was used as this approach has been demonstrated to be effective when only small numbers of occurrence localities are available. In this method, each observed locality is excluded once from the dataset used to build the model, and its predictive performance is assessed based on the ability of the model to predict each single locality excluded in turn. It requires the application of a threshold, for dichotomizing the continuous map output surface into presence and absence values, to assess the model performance by predicting the single excluded presence point from the training dataset. The 10 th percentile training presence threshold was used. It sets as threshold the value that excludes the $10 \%$ of the predicted locations having the lowest predicted values, as these may represent recording errors and/or ephemeral populations (Morueta-Holme et al., 2010; Radosavljevic and Anderson, 2014). The predictive ability of models was compared using the test suggested by Pearson et al. (2007). The functional relationship between I. ricinus presence and the input environmental variables was evaluated and compared through inspection of the MaxEnt response graphs. The relative importance of each environmental variable in the models was evaluated by jackknife testing of the variable importance procedure, as implemented in MaxEnt. Finally, differences between Model 1 and Model 2 outputs were assessed by quantifying niche overlap, using the Ecological Niche Modelling Tools (ENMTools) (Warren et al., 2010). Niche overlap was calculated using Schoener's D statistic index. The metric ranges from 0 (species having completely discordant predicted distribution) to 1 (species with identical predicted distribution) (Warren et al., 2008).

\section{Environmental variables}

Based on the biological and ecological knowledge on I. ricinus requirements, an initial set of environmental factors was chosen as potential explanatory variables of tick distribution. The variables initially included were altitude (obtained from the United States Geological Survey), slope, aspect (derived from ArcGIS ${ }^{\circledR}$ software), land cover (extracted from the Corine Land Cover 2006 raster map), and rainfall (downloaded from the WorldClim database that reports average monthly rainfall data at a $1 \mathrm{~km}^{2}$ resolution, based on interpolated climate data from weather stations). Finally, normalized difference vegetation index (NDVI), and day and night time temperature were derived from the Moderate Resolution Imaging Spectroradiometer (Table 1).

To reduce issues related to over-fitting and collinearity in the environmental variables, only a subset of potential predictors was chosen from the full set to reduce the number of variables (Elith $e t$ al., 2010). An initial explorative analysis was performed to exclude the variables with the lowest variability in the study area. The correlation among the variables was tested using Pearson's correlation analysis (software IBM SPSS statistics 20). Among those highly correlated $\left(\mathrm{R}^{2} \geq 0.80\right)$, only the most meaningful ones from a biological point of view were selected for inclusion in the models. 


\section{Results}

\section{Tick collection and detection of pathogens}

I. ricinus was observed at $28(53.8 \%)$ out of 52 monitored sites. Besides, 63 (33.5\%) out of 188 dragging sessions were positive for this species. Overall, 341 specimens were collected: 54 adults, 95 nymphs and 192 larvae, with an overall average density of 2.05 ticks $/ 100 \mathrm{~m}^{2}$. Molecular analysis showed a high prevalence of Borrelia burgdorferi s.1. (15/54 positive adults, 5/35 positive pools of nymphs and $2 / 29$ positive pools of larvae) and of Rickettsia spp. (11/54 positive adults, $10 / 35$ positive pools of nymphs and $9 / 29$ positive pools of larvae).

\section{Comparison of tick monitoring strategies}

The results of the comparison among the different monitoring strategies and the results obtained from the complete dataset are shown in Table 2. Strategy 1 permitted collection of more specimens than Strategy 2, but a lower number of pools were analysed at the end with this strategy. This was due to the occasional recovery of many larvae $(n=120)$ in two samplings (July and August 2010) at one single site, and all these larvae were grouped in a few pools according to the defined methodology. The occurrence of the two pathogens (Borrelia burgdorferi s.l. and Rickettsia spp.) was detected using both strategies and their prevalence values were not significantly different from those obtained using the complete dataset. However, Strategy 1 estimated a higher prevalence than Strategy 2; for Rickettsia spp. this difference was significant.

\section{Tick habitat suitability model}

Based on the exploratory and correlation analyses (Pearson correlation test was used to exclude highly correlated environmental predictors, retaining only those with the perceived highest biological meaningfulness for ticks) the final set of predictor variables included the following variables for the two models: the NDVI seasonal averages for spring and autumn and the land surface temperature during the light hours $\left(\mathrm{LST}_{\text {day }}\right)$ in the summer.

The MaxEnt produced tick habitat suitability maps (binary and continuous outputs) for Model 1 and 2 are shown in Figure 2. Both models performed well as measured by the leave-one-out validation approach, i.e. 10 out of 12 excluded points predicted for Model $1(\mathrm{P}<0.01)$ and 21 out of 24 for Model $2(\mathrm{P}<0.001)$. The overlap among the model continuous outputs was high (Schoener's $\mathrm{D}=0.93$ ) indicating that the model predictions did not change significantly with respect to the input training dataset (12 and 24

Table 1. Preliminary set of environmental variables selected for developing the models.

\begin{tabular}{|c|c|}
\hline Variable & Source \\
\hline Altitude & $\begin{array}{l}\text { Digital Elevation Model (DEM) GTOPO30, obtained from United States Geological Survey (USGS) Earth Resources Observation } \\
\text { and Science (EROS) Data Center (http://rda.ucar.edu/datasets/ds758.0/) }\end{array}$ \\
\hline Aspect, Slope, Hill shade & DEM GTOPO30, obtained using the spatial analyses toolset of ArcGIS ${ }^{\circledR}$ software version 10.2 (ESRI, Redlands, CA, USA) \\
\hline Land Cover & $\begin{array}{l}\text { Corine Land Cover } 2006 \text { raster map (CLC), obtained from the European Environment Agency } \\
\text { (http://www.eea.europa.eu/data-and-maps/data/corine-land-cover-2006-clc2006-100-m-version-12-2009\#tab-gis-data) }\end{array}$ \\
\hline $\begin{array}{l}\mathrm{NDVI}^{*} \\
\mathrm{LST}_{\text {day }}^{\circ} \\
\mathrm{LST}_{\text {night }}^{\#}\end{array}$ & $\begin{array}{l}\text { Moderate Resolution Imaging Spectroradiometer (MODIS) } \\
\text { onboard the Terra satellite (https://pdaac.usgs.gov/) }\end{array}$ \\
\hline $\mathrm{BIO}$ & WorldClim database (http://www.worldclim.org) \\
\hline $12-14$ and $16-19^{\S}$ & \\
\hline
\end{tabular}

Table 2. Number of positive sites, ticks, pools and pathogens prevalence according to different monitoring strategies.

\begin{tabular}{|c|c|c|c|}
\hline Site/Collection/Outcome & $\begin{array}{l}\text { Complete data } \\
2009-2010\end{array}$ & $\begin{array}{l}\text { Strategy } 1 * \\
2010\end{array}$ & $\begin{array}{l}\text { Strategy } 2 \\
2009\end{array}$ \\
\hline Sampled sites & 52 & 16 & 52 \\
\hline Number of dragging sessions & 188 & 112 & 52 \\
\hline Positive sites & 28 & 12 & 24 \\
\hline $\begin{array}{l}\text { Number of collected I. ricinus } \\
\text { (adults/ nymphs/larvae) }\end{array}$ & $\begin{array}{l}341 \\
(54 / 95 / 192)\end{array}$ & $\begin{array}{l}200 \\
(15 / 25 / 160)\end{array}$ & $\begin{array}{l}96 \\
(30 / 57 / 9)\end{array}$ \\
\hline Number of pools analysed & 118 & 46 & 50 \\
\hline $\begin{array}{l}\text { Borrelia burgdorferi s.l. } \\
\text { Positive/analysed pools (\%) (95\% CI) }\end{array}$ & $\begin{array}{l}22 / 118(18.6) \\
\text { (CI: } 11.6-25.7)\end{array}$ & $\begin{array}{l}11 / 46(23.9) \\
(\mathrm{CI}: 11.6-36.2)\end{array}$ & $\begin{array}{l}5 / 50(10.0) \\
(\mathrm{CI}: 1.7-18.3)\end{array}$ \\
\hline $\begin{array}{l}\text { Rickettsia spp. } \\
\text { Positive/analysed pools (\%) (95\% CI) }\end{array}$ & $\begin{array}{l}30 / 118(25.4) \\
(\mathrm{CI}: 17.6-33.3)\end{array}$ & $\begin{array}{l}19 / 46(41.3) \\
(\mathrm{CI}: 27.0-55.5)\end{array}$ & $\begin{array}{l}8 / 50(16.0) \\
(\mathrm{CI}: 5.8-26.7)\end{array}$ \\
\hline
\end{tabular}

*Model 1: permanent sites - April to October; ${ }^{\circ}$ Model 2: temporary sites - April to October. 
points of occurrences, respectively).

The jackknife test of variable importance showed that $\mathrm{NDVI}_{\text {spring }}$ was the most influential variable, in both models, indicating that NDVI is the most important predictor for tick distribution in the current study. It was also the environmental variable that decreased the gain (a measure of goodness of fit closely related to deviance) the most when omitted, which therefore is a reflection that this variable in isolation is the strongest contributor (Table 3 ).
The set of response graphs produced by generating a model using only the corresponding variable, were similar for the two models and showed that the highest relative probability of I. ricinus presence was predicted in areas with more dense vegetation cover during autumn and spring resulting in higher NDVI values $\left(>0.85\right.$ and $>0.78$, respectively) and lower $\mathrm{LST}_{\text {day }}$ values $\left(\mathrm{T}^{\circ}<24^{\circ} \mathrm{C}\right)$.
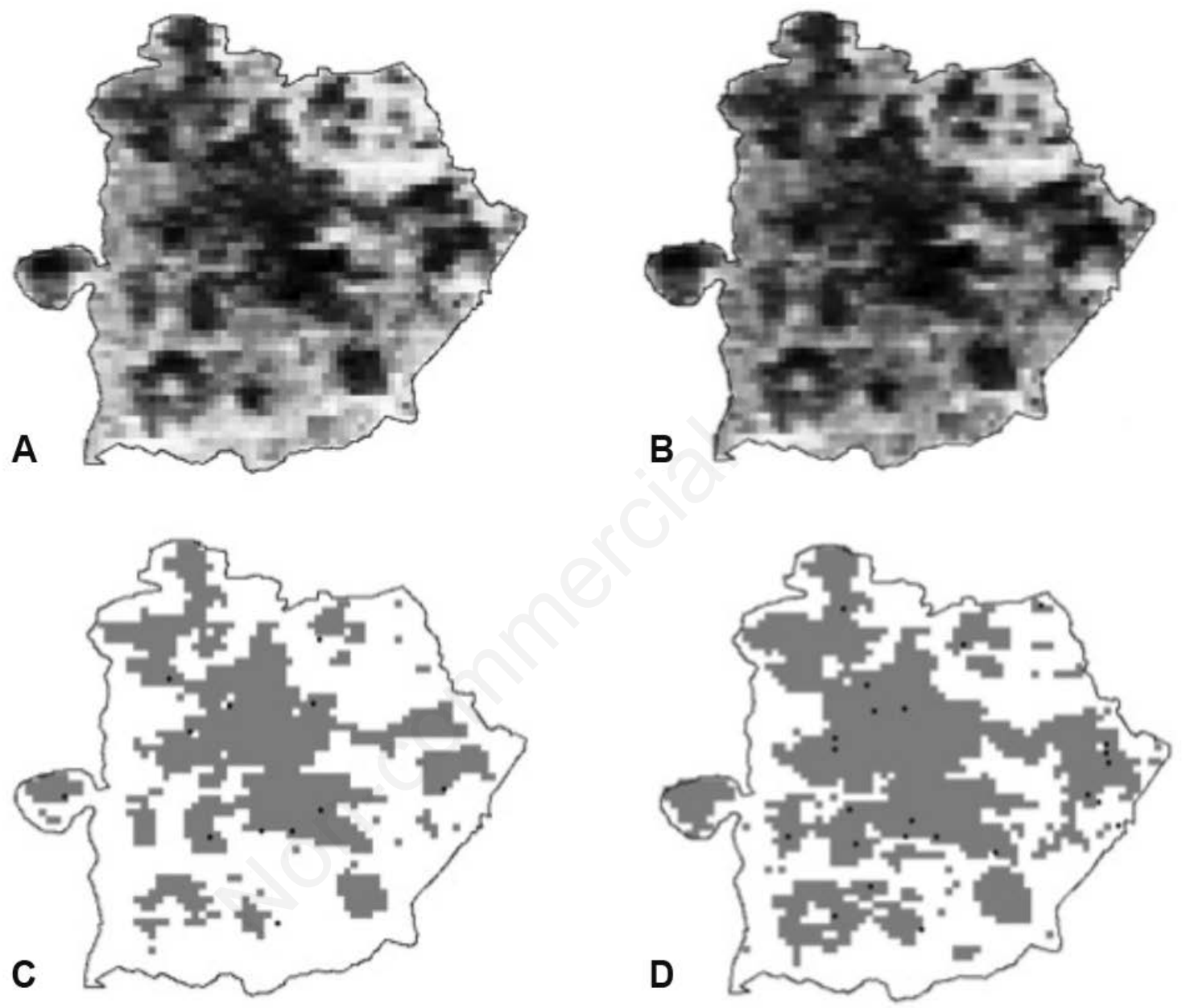

Figure 2. Habitat suitability maps of I. ricinus in Colli Euganei Regional Park, Italy obtained by two models. The upper images represent the continuous outputs of model 1 (A) and model 2 (B), the lower images show the binary outputs and the training points used for developing model 1 (C) and model 2 (D). Darker colors indicate higher habitat suitability.

Table 3. The results of jackknife test of variable importance as measured by the regularized training gain for $I$. ricinus for the two MaxEnt models.

\begin{tabular}{lllll} 
& \multicolumn{2}{c}{ Training gain* } & \multicolumn{2}{c}{ Training gain $^{\circ}$} \\
Variable & Without variable & With only variable & Without variable & 0.05 \\
LST $_{\text {day }}$ in summer & 0.42 & 0.04 & 0.27 & 0.27 \\
NDVI in spring & 0.30 & 0.40 & 0.12 & 0.12 \\
\hline NDVI in autumn & 0.40 & 0.30 & 0.27 & With variable \\
\hline
\end{tabular}

$\mathrm{LST}_{\text {day, }}$ Land Surface Temperature during light hours; NDVI, normalized difference vegetation index. ${ }^{*}$ Model 1: 12 sites, area under the curve $=0.78$ (averaged over the replicate runs); ${ }^{\circ}$ Model $2: 24$ sites, area under the curve $=0.73$ (averaged over the replicate runs). 


\section{Discussion}

Ixodes ricinus was found to be the most prevalent tick species in the study area, but at low density (about 2 ticks $/ 100 \mathrm{~m}^{2}$ ) compared to pre-alpine areas of North-eastern Italy (Nazzi et al., 2010; Tagliapietra et al., 2011). This may be due to environmental characteristics that are not the optimal for this tick species, and to limited presence of wild ruminants.

The comparison between the two sampling strategies in the present study suggests that monitoring temporary sites only once/year (Strategy 2) allows the discovery of more positive sites and seems to ensure more cost-effectiveness in term of number of pools analysed: 50 pools with 52 dragging sessions in Strategy $2 \mathrm{vs}$ 46 pools with 112 sessions in Strategy 1. The more pools available for pathogens detection, the more significant the results of molecular analyses. Strategy 1 seems to over-estimate the true prevalence and this may be due to sites with many positive ticks that are repeatedly sampled. However, both strategies detected the pathogens circulating in the area and the estimated prevalence was not significantly different from what was estimated using the complete dataset. Of note, Strategy 2 obtained this result with about one-fourth of the dragging sessions of the whole survey. Clearly, a reduction in sampling effort corresponds to an abatement of sampling-costs (reduction of travel and operators costs), which are one of the more relevant expenditures of monitoring, as previously demonstrated (Capelli et al., 2012). Monitoring fewer permanent sites (Strategy 1) may help in a sound description of tick species seasonality, but it represents an additional cost when the main objectives of surveillance activity are the development of a risk map (habitat suitability) and the detection of TBPs.

Overall, the models demonstrated a good predictive ability, which increased with the number of sites used to train the model, confirming the outcome of previous studies (Hernandez et al., 2006; Pearson et al., 2007; Wisz et al., 2008). However, the MaxEnt predictions based on the two sub-sets of data obtained a high niche overlap index and both produced realistic distribution maps, even the one with a low number of presence sites $(n=12)$ as input.

The SDM approach identified a number climatic and other environmental conditions suitable for I. ricinus and, as such, reflects the known ecological requirements of the $I$. ricinus species. The most important variable for development of the models was $\mathrm{NDVI}_{\text {spring, }}$, followed by the NDVI $\mathrm{Nutumn}_{\text {. }}$. Spring corresponds to the period of peak tick activity, whereas autumn represents both the period of the second peak and the beginning of diapause, according to climatic condition of northern Italy (Piccolin et al., 2006; Ceballos et al., 2014). These results are consistent with the biological and ecological requirements of ticks, which are sensitive to desiccation during the environmental phases of their life cycle and therefore can survive only in areas with good vegetation cover, which provides relatively high moisture levels (Gray, 1998). Furthermore, the results are consistent with previous studies demonstrating that NDVI is a good predictor for I. ricinus ticks, being a measure of photosynthetic activity of vegetation and therefore a good proxy for soil moisture (Wang et al., 2007; Ruiz-Fons et al., 2012; Estrada-Peña et al., 2013; Ceballos et al., 2014). We also found that that low day-time summer temperatures were associated with higher relative probability of $I$. ricinus presence. This finding confirms the hypothesis generated by our previous preliminary ecological analysis, based only on field-collected environmental data (Drigo et al., 2011), that a significant association between the presence of adult ticks and relatively low temperatures exist. These results suggest that the main limiting factor in this area is represented by the degree of heat during summer and dryness during spring and autumn, in place of the cold winter of the prealpine environment.

\section{Conclusions}

The implementation of cost-effective sampling strategies may serve to optimize available resources, achieving an efficient and cost-effective tick and TBP surveillance. In this study the analyses of tick data collected during a 2-year field investigation demonstrated that TBP detection and map development can be obtained in the study area with a reduced sampling effort. Based on our findings, we suggest that the most cost-effective approach is to monitor tick presence only once, at an appropriate number of sites relative to the study area, and then use the positive sites to develop tick habitat suitability maps, by means of an SDM-remote sensing approach. A wider application of this kind of integrated approach is foreseen, but needs to be tested in other areas at risk of ticks' infestation, to prove its effectiveness in large-scale survey plans.

\section{References}

Bergquist R, Stensgaard AS, Rinaldi L, 2018. Vector-borne diseases in a warmer world: will they stay or will they go? Geospat Health 13:1-2.

Braks M, van der Giessen J, Kretzschmar M, van Pelt W, Scholte EJ, Reusken C, Zeller H, van Bortel W, Sprong H, 2011. Towards an integrated approach in surveillance of vectorborne diseases in Europe. Parasit Vectors 4:192.

Capelli G, Ravagnan S, Montarsi F, Ciocchetta S, Cazzin S, Porcellato E, Babiker AM, Cassini R, Salviato A, Cattoli G, Otranto D, 2012. Occurrence and identification of risk areas of Ixodes ricinus-borne pathogens: a cost-effectiveness analysis in north-eastern Italy. Parasit Vectors 5:61.

Ceballos LA, Pintore MD, Tomassone L, Pautasso A, Bisanzio D, Mignone W, Casalone C, Mannelli A, 2014. Habitat and occurrence of ixodid ticks in the Liguria region, northwest Italy. Exp Appl Acarol 64:121-35.

Corine Land Cover raster map (CLC), 2006. European Environment Agency. Available from: http://www.eea. europa.eu/data-and-maps/data/corine-land-cover-2006clc2006-100-m-version-12-2009\#tab-gis-data

Courtney JW, Kostelnik LM, Zeidner NS, Massung RF, 2004. Multiplex real-time PCR for detection of anaplasma phagocytophilum and Borrelia burgdorferi. J Clin Microbiol 42:3164-8.

Cringoli G, Iori A, Rinaldi L, Veneziano V, Genchi C, 2005. Zecche - Mappe Parassitologiche. Rolando, Naples, Italy. 263 pp. Available from: http://www.parassitologia.unina.it/PDF/ Zecche.pdf Accessed: September 2018.

Dantas-Torres F, Chomel BB, Otranto D, 2012. Ticks and tickborne diseases: a one health perspective. Trends Parasitol 28:437-46.

Digital Elevation Model (DEM) GTOPO30. United States Geological Survey (USGS) Earth Resources Observation and Science (EROS) Data Center. Available from: http://rda. ucar.edu/datasets/ds758.0/ 
Drigo M, Martini M, Ciocchetta S, Signorini M, Frangipane di Regalbono A, Cassini R, 2011. Active monitoring of ticks and tick-borne zoonotic pathogens (TBP) as part of a "one-health" surveillance strategy: a case study from the Colli Euganei regional park, north-eastern Italy. Ital J Med Trop 15:75-82. Available from: www.simetweb.eu/document/3633 Accessed: September 2018.

Elith J, Leathwick JR, 2009. Species Distribution models: ecological explanation and prediction across space and time. Annu Rev Ecol Evol Syst 40:677-97.

Elith J, Kearney M, Phillips S, 2010. The art of modelling rangeshifting species. Methods Ecol Evol 1:330-42.

Estrada-Peña A, Estrada-Sánchez A, Estrada-Sánchez D, De la Fuente J, 2013. Assessing the effects of variables and background selection on the capture of the tick climate niche. Int J Health Geogr 12:43.

Gray JS, 1998. The ecology of ticks transmitting Lyme borreliosis. Exp Appl Acarol 22:249-58.

Gray JS, Dautel H, Estrada-Peña A, Kahl O, Lindgren E, 2009. Effect of climate change on ticks and tick-borne diseases in Europe. Interdisc Perspect Infect Dis 2009:593232.

Gray JS, Zintl A, Hildebrandt A, Hunfeld KP, Weiss L, 2010. Zoonotic babesiosis: Overview of the disease and novel aspects of pathogen identity. Ticks Tick Borne Dis 1:3-10.

Hernandez PA, Graham CH, Master LL, Albert DL, 2006. The effect of sample size and species characteristics on performance of different species distribution modeling methods. Ecography 29:773-85.

Illoldi-Rangel P, Rivaldi CL, Sissel B, Trout Fryxell R, GordilloPérez G, Rodríguez-Moreno A, Williamson P, Montiel-Parra G, Sánchez-Cordero V, Sarkar S, 2012. Species distribution models and ecological suitability analysis for potential tick vectors of lyme disease in Mexico. J Trop Med 2012:959101.

Manilla G, Iori A, 1992. Illustrated key to the ticks of Italy. I. Larval stages of the species of the Ixodinae subfamily (Acari, Ixodoidea, Ixodidae). Parassitologia 34:83-95.

Medlock JM, Hansford KM, Bormane A, Derdakova M, EstradaPeña A, George JC, Golovljova I, Jaenson TG, Jensen JK, Jensen PM, Kazimirova M, Oteo JA, Papa A, Pfister K, Plantard O, Randolph SE, Rizzoli A, Santos-Silva MM, Sprong H, Vial L, Hendrickx G, Zeller H, Van Bortel W, 2013. Driving forces for changes in geographical distribution of Ixodes ricinus ticks in Europe. Parasit Vectors 6:1.

Moderate Resolution Imaging Spectroradiometer (MODIS), onboard the Terra satellite. Available from: https://lpdaac. usgs.gov/

Morueta-Holme N, Fløjgaard C, Svenning JC, 2010. Climate change risks and conservation implications for a threatened small-range mammal species. PloS One 5:e10360.

Mughini-Gras L, Mulatti P, Severini F, Boccolini D, Romi R, Bongiorno G, Khoury C, Bianchi R, Montarsi F, Patregnani T, Bonfanti L, Rezza G, Capelli G, Busani L, 2014. Ecological niche modelling of potential West Nile virus vector mosquito species and their geographical association with equine epizootics in Italy. Ecohealth 11:120-32.

Mwase ET, Stensgaard AS, Nsakashalo-Senkwe M, 2014. Mapping the geographical distribution of lymphatic filariasis in Zambia. PloS Negl Trop Dis 8:e2714.

Nazzi F, Martinelli E, Del Fabbro S, Bernardinelli I, Milani N, Iob
A, Pischiutti P, Campello C, D’Agaro P, 2010. Ticks and Lyme borreliosis in an alpine area in northeast Italy. Med Vet Entomol 24:220-6.

Pearson RG, Raxworthy CJ, Nakamura M, Peterson AT, 2007. Predicting species distribution from small numbers of occurrence records: a test case using cryptic geckos in Madagascar. J Biogeogr 34:102-17.

Phillips SJ, Anderson RP, Schapire RE, 2006. Maximum entropy modeling of species geographic distributions. Ecol Model 190:231-59.

Phillips SJ, Dudík M, 2008. Modeling of species distributions with MaxEnt: new extensions and a comprehensive evaluation. Ecography 31:161-75.

Phillips SJ, Dudik M, Shapire RE, 2004. A maximum entropy approach to species distribution modeling. In: Greiner R, Schuurmans D, eds. International conference on machine learning, 2004: Proceedings of the 21st International Conference on machine learning, 2004 July 4-8, Banff, Alberta, Canada. ACM Press, New York. pp 655-662.

Piccolin G, Benedetti G, Doglioni C, Lorenzato C, Mancuso S, Papa N, Pitton L, Ramon MC, Zasio C, Bertiato G, 2006. A Study of the presence of B. burgdorferi, Anaplasma (previously Ehrlichia) phagocytophilum, Rickettsia, and Babesia in Ixodes ricinus collected within the territory of Belluno, Italy. Vector Borne Zoonotic Dis 6:24-31.

Radosavljevic A, Anderson RP, 2014. Making better MaxEnt models of species distributions: complexity, overfitting and evaluation. J Biogeogr 41:629-43.

Regnery RL, Spruill CL, Plikaytis BD, 1991. Genotypic identification of rickettsiae and estimation of intraspecies sequence divergence for portions of two rickettsial genes. J Bacteriol 173:1576-89.

Ruiz-Fons F, Fernández-de-Mera IG, Pelayo Acevedo P, Gortázar C, de la Fuente J, 2012. Factors driving the abundance of Ixodes ricinus ticks and the prevalence of zoonotic I. ricinusborne pathogens in natural foci. Appl Environ Microbiol 78:2669-76.

Signorini M, Cassini R, Drigo M, Frangipane di Regalbono A, Pietrobelli M, Montarsi F, Stensgaard AS, 2014. Ecological niche model of Phlebotomus perniciosus, the main vector of canine leishmaniasis in north-eastern Italy. Geospat Health 9:193-201.

Tagliapietra V, Rosà R, Arnoldi D, Cagnacci F, Capelli G, Montarsi F, Hauffe HC, Rizzoli A, 2011. Saturation deficit and deer density affect questing activity and local abundance of Ixodes ricinus (Acari, Ixodidae) in Italy. Vet Parasit 183:114-24.

Wang X, Xie H, Guan H, Zhou X, 2007. Different responses of MODIS-derived NDVI to root-zone soil moisture in semi-arid and humid regions. J Hydrol 340:12-24.

Warren DL, Glor RE, Turelli M, 2008. Environmental niche equivalency versus conservatism: quantitative approaches to niche evolution. Evolution 62:2868-83.

Warren DL, Glor RE, Turelli M, 2010. ENM Tool: a toolbox for comparative studies of environmental niche models. Ecography 33:607-11.

Wisz MS, Hijmans RJ, Li J, Peterson AT, Graham CH, Guisan A, 2008. Effects of sample size on the performance of species distribution models. Divers Distrib 14:763-73. 